\title{
Ammonia gas sensor response of a vertical zinc oxide nanorod-gold junction diode at room temperature
}

Ying Tu, ${ }^{\text {a }}$ Candice Kyle, ${ }^{a}$ Hui Luo,,${ }^{\mathrm{a} d}$ De-Wen Zhang, ${ }^{\mathrm{b}}$ Anirban Das, ${ }^{\mathrm{a}}$ Joe Briscoe, ${ }^{\mathrm{a}}$ Steve Dunn, ${ }^{\mathrm{c}}$ Maria-Magdalena Titirici, ${ }^{\mathrm{d}}$ and Steffi Krause *a

E-mail: $\underline{\text { s.krause@qmul.ac.uk }}$

a. School of Engineering and Materials Science, Queen Mary University of London, 327 Mile End Road, London, E1 4NS, UK. E-mail: s.krause@qmul.ac.uk

b. Institute of Medical Engineering, School of Basic Medical Sciences, Health Science Center, Xi'an Jiaotong University, Xi'an, 710061, China.

c. Chemical and Energy Engineering, London South Bank University, 103 Borough Road, London, SE1 0AA, UK.

d. Department of Chemical Engineering, Imperial College London, South Kensington Campus, London, SW7 2AZ, UK.

Abstract: Conventional metal oxide semiconductor (MOS) gas sensors have been investigated for decades to protect our life and property. However, the traditional devices can hardly fulfil the requirements of our fast developing mobile society, because the high operating temperatures greatly limit their applications in battery-loaded portable systems that can only drive devices with low power consumption. As ammonia is gaining importance in the production and storage of hydrogen, there is an increasing demand for energy-efficient ammonia detectors. Hence, in this work, a Schottky diode resulting from the contact between zinc oxide nanorods and gold is designed to detect gaseous ammonia at room temperature with a power consumption of $625 \mu \mathrm{W}$. The Schottky diode gas sensors benefit from the change of barrier height in different gases as well as the catalytic effect of gold nanoparticles. This diode structure - fabricated without expensive interdigitated electrodes and displaying excellent performance at room temperature provides a novel method to equip mobile devices with MOS gas sensors.

Keywords: gas sensor, Schottky diode, ammonia, zinc oxide nanorods, gold nanoparticles

Ammonia $\left(\mathrm{NH}_{3}\right)$ is one of the most important alkaline gases in the atmosphere. It is a critical nitrogen source that plays an important role in the global biogeochemical nitrogen cycle, climate change as well as human health. ${ }^{1,2} \mathrm{NH}_{3}$ has been used widely as a feedstock for nitrogen in agriculture and as a refrigerant and has recently been gaining importance as an excellent source 
for hydrogen in energy production, for example hydrogen storage and generation in vehicular applications. ${ }^{3-5}$ The use of $\mathrm{NH}_{3}$ for on-board hydrogen storage necessitates the development of new sensor technologies for its detection. As the alkaline gas can cause eye irritation at 20 parts per million (ppm), ${ }^{6}$ it is essential to monitor and maintain the $\mathrm{NH}_{3}$ concentration below the exposure limit of 5-50 ppm to prevent irritations or burns to eyes, the nose, the throat and the skin. The annual emission of $\mathrm{NH}_{3}$ has been growing due to human activities in the last few decades. Therefore, there is growing need for the development of $\mathrm{NH}_{3}$ sensors with detection limits down to $20 \mathrm{ppm}$. Metal oxide semiconductor (MOS) gas sensors have recently received a lot of attention due to their ease of processing, low cost, fast response and high selectivity. ${ }^{7-10}$ A major issue of MOS gas sensors is the high operating temperature above $350{ }^{\circ} \mathrm{C}$, which limits their application due to the high energy requirement and the risk of ignition at high temperatures. ${ }^{11-13}$ For conventional MOS gas sensors, the conductometric response is low at room temperature. Two main factors might cause the poor behaviour: (1) the amount of oxygen adsorption species on the sensing layer is small; and (2) at temperatures below $100{ }^{\circ} \mathrm{C}$, oxygen molecules prefer to ionize to $\mathrm{O}_{2}^{-}$rather than the more active species $\mathrm{O}^{-}$or $\mathrm{O}^{2-}$, which largely restricts their activity when exposed to analytes. ${ }^{14}$ At low temperatures, reaction products such as water and other small intermediate organic compounds remain at the semiconductor surface rather than desorbing, therefore, the recovery time is much longer at room temperature than at high temperatures. The residue on the sensing surface inhibits the re-adsorption of oxygen as well as slowing electron movement in the semiconductor's conduction band.

Recently, metal oxide semiconductor (MOS) room-temperature gas sensors have been achieved either under ultraviolet (UV) illumination ${ }^{15-18}$ or with vibration. ${ }^{8,19-21}$ UV illumination improves gas sensor sensitivity because the photo-induced carriers may facilitate the reaction between the ionized oxygen and analyte molecules. UV light with high intensity can also heat up the device. Sunghoon Park et al. presented an $\mathrm{NO}_{2}$ gas sensor made of $\mathrm{ZnO}-\mathrm{SnO}_{2}$ composite, which has a 2-3 fold enhancement in response due to UV illumination at room temperature. ${ }^{18}$ However, the stability under intensive UV illumination was demonstrated to be poor. More recently, $\mathrm{ZnO}$ nanostructures decorated with metal nanoparticles have been reported to improve $\mathrm{ZnO}$ gas sensing properties, where the catalytic properties of metals such as gold, platinum and palladium facilitate the resistance changes occurring on the surface in response to different gases. ${ }^{22-31}$ However, most of these devices need light illumination or high working temperatures. 
None of them have considered the practical requirements of low power consumption and portability. One notable exception is the report by Shingange et al. that shows that gold nanoparticle modified $\mathrm{ZnO}$ nanorods had responsivity and selectivity to ammonia at room temperature when the gold loading level was $0.5 \mathrm{wt} \%{ }^{32}$ The enhanced performance by gold nanoparticles was assumed to be due to a spill-over effect that allowed dissociated molecules to migrate from the gold to the $\mathrm{ZnO}$ surface.

$\mathrm{ZnO}$ is one of the most studied materials for gas sensing devices due to its wide band gap, high carrier mobility as well as low cost and simple synthesis processes. ${ }^{33-36}$ Nanostructured $\mathrm{ZnO}$ with specific size and dimensions has been demonstrated to be suitable for gas sensing devices originating from the potential for a large surface-to-volume ratio, high specific surface area, large amount of surface active sites, as well as the recently recognized effect of certain crystal facets having particularly high surface reactivity. ${ }^{37}$ Many examples of different kinds of nanostructures have been investigated and assembled into gas sensors: nanoparticles, ${ }^{16}$ nanorods, ${ }^{17,38}$ nanowire, ${ }^{39,40}$ nanoplates, ${ }^{35}$ as well as urchin-like structures ${ }^{41}$ being the most common.

Schottky diodes can detect volatile organic compounds (VOCs) based on the observation of the shifts in the current-voltage $(I-V)$ curve caused by the reaction of analytes on the metalsemiconductor interface which alters the Schottky barrier height at the interface. ${ }^{42-44}$ The barrier height of a metal-semiconductor (n-type) is smaller in a reducing gas than in air. Kalantar-Zadeh and co-workers reported a $\mathrm{Pt} / \mathrm{WO}_{3}$ film Schottky-based hydrogen and ethanol sensors in 2015, and the best performance to $1 \%$ hydrogen was a voltage shift of $1.67 \mathrm{~V}$ at an operating temperature of $200{ }^{\circ} \mathrm{C}$. ${ }^{43}$ Although the Schottky diode showed good gas sensing properties, the working temperature was still high because the film morphology of $\mathrm{WO}_{3}$ provided limited surface area and insufficient active sites. Overall, Schottky diode-based gas sensors have received rather limited attention.

$\mathrm{ZnO}$ is one of the most common n-type semiconductors used in Schottky junction devices ${ }^{45,46}$ when in contact with a large work function noble metal such as gold ( $\mathrm{Au}$ ). The versatile $\mathrm{ZnO}$ morphologies provide multiple choices for high-surface-area devices. In this work, inspired by the barrier height change mechanism in Schottky diodes, a room temperature gas sensor made of a junction of $\mathrm{ZnO}$ nanorods and a gold contact has been developed for low temperature $\mathrm{NH}_{3}$ 
detection. The high surface area of the nanorods and the vertical structure of the Schottky diode reported here for the first time facilitate a shift of the barrier height at room temperature and, thereby, offer a solution for the high working temperature issue in MOS gas sensors. $\mathrm{ZnO}$ nanorods were grown using a simple solution-based method. Schottky diodes were obtained by thermally evaporating gold on top of the nanorods. The evaporation process did not only produce a contact on the $\mathrm{ZnO}$, but also resulted in the decoration of the $\mathrm{ZnO}$ nanorod with catalytic gold nanoparticles. Moreover, the newly developed device does not need the high-cost interdigitated electrodes that conventional gas sensors have to use.

(a)

(b)
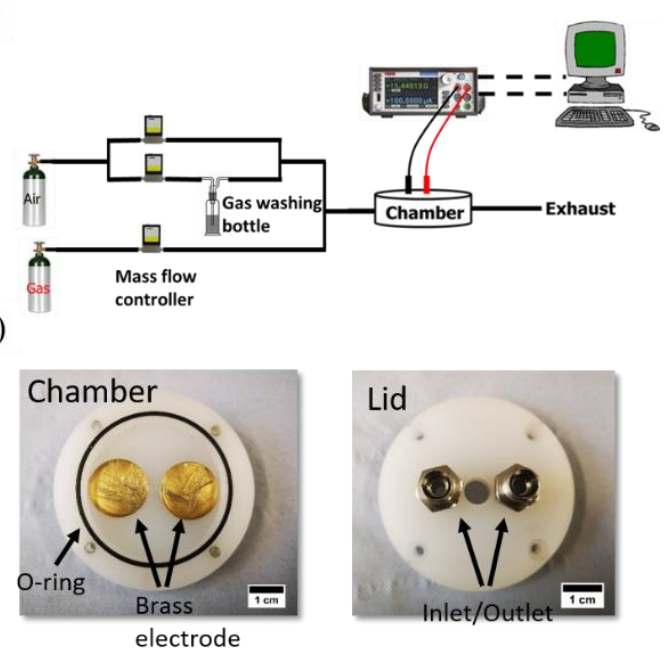

Figure 1 (a) Schematic of custom-designed gas sensor test rig. (b) The testing chamber was custom designed with a volume of $4 \mathrm{~mL}$.

\section{Experimental}

\section{Synthesis of $\mathrm{ZnO}$ nanorods and device fabrication}

All the chemicals were purchased from Sigma-Aldrich Co., Ltd U.K. unless stated otherwise and used without any further purification. $\mathrm{ZnO}$ nanorods were produced on fluorine doped tin oxide (FTO)-coated glass $(2 \mathrm{~cm} \times 2 \mathrm{~cm}, 15 \Omega / \mathrm{sq}$, Solaronix SA, Switzerland) using a solution method as described previously. ${ }^{47}$ After the synthesis, $\mathrm{ZnO}$ nanorods were annealed in a box furnace (Lenton, U.K.) at $350{ }^{\circ} \mathrm{C}$ in air for $1 \mathrm{~h}$. The $\mathrm{ZnO} / \mathrm{Au}$ (Au purity > $99.99 \%$ ) Schottky diode devices were completed by evaporating a gold contact (area $=0.5 \mathrm{~cm}^{2}$ ) through a custom-designed stripe patterned mask of approximately $150 \mathrm{~nm}$ equivalent thickness (on a planar surface) onto the $\mathrm{ZnO}$ nanorods 
using a vacuum thermal evaporator (E306A, Edwards) at a pressure $<10^{-5}$ Bar and with an average rate of $1.5 \mathrm{~nm} / \mathrm{s}$. To prevent short circuits, regions around the active area were blocked by drop coating poly(methyl methacrylate) (PMMA, average MW 120000 $\mathrm{g} / \mathrm{mol}$ ), which was dissolved to form a $9 \mathrm{wt} \%$ solution in methoxybenzene (assay 99\%). For comparison, $\mathrm{ZnO}$ nanorods were produced on interdigitated electrode (IDE) (DRPIDEAU200, DropSens, Spain) substrates using the same recipe as that on the FTO-coated glass.

\section{Characterization and gas sensor measurements}

The morphology of $\mathrm{ZnO}$ nanorods was examined using a scanning electron microscope (SEM, FEI, Inspect F). The gold nanoparticle distribution on the $\mathrm{ZnO}$ nanorods was analysed using transmission electron microscopy (TEM, JEOL JEM 2010). The average size of Au nanoparticles was obtained by measuring 50 randomly selected nanoparticles from a TEM image using ImageJ. The $I-V$ characteristics of the devices were measured in the range of $-1.5 \mathrm{~V}$ to $+1.5 \mathrm{~V}$ using a source meter (Keithley 2400) which is controlled by a custom-written LabVIEW program.

Figure 1a shows the schematic of the gas sensor test platform. The gas sensor devices were placed in a custom-designed chamber (volume $\approx 4 \mathrm{~mL}$ ) with a gas inlet and outlet (Figure $1 \mathrm{~b}$ ). The chamber can be sealed with a rubber O-ring and has two brass plates with contacts that are connected to a source meter (Keithley 2400). The device electrodes were connected with copper tape, and then silver paint was used to connect these to the brass plates to create ohmic contacts. Gas was introduced into the chamber by mass flow controllers (1179A, MKS Instruments, USA); a flow rate $1 \mathrm{~L} / \mathrm{min}$ was recorded by a gas flowmeter. Different gas concentrations were obtained by diluting the gases with dry synthetic air. The humidity was adjusted by mixing dry with wet air in the appropriate ratios. The current change of the sensor devices was monitored at a constant $0.5 \mathrm{~V}$ using the source meter that was controlled by a custom-written LabVIEW program. All the gases were diluted with synthetic air and purchased from The BOC Group, U.K. All the devices were measured at ambient temperature (about $22{ }^{\circ} \mathrm{C}$ ).

\section{Results and discussion}

\section{Characterization of $\mathrm{ZnO} / \mathrm{Au}$ Schottky diodes}


Figure 2a shows a $\mathrm{ZnO} / \mathrm{Au}$ Schottky diode gas sensor device and Figure $2 \mathrm{~b}$ is a schematic of its side view. The scanning electron microscope (SEM) image of the gold-coated area (indicated by the red dot in Figure 2a) in Figure 2c illustrates a rough surface with some gold particles visible on the $\mathrm{ZnO}$ nanorods. The corresponding cross-sectional view in Figure $2 \mathrm{e}$ shows a clear gold covering on the top of the $\mathrm{ZnO}$ nanorods, which was used as an electrode. No gold is observed on the bottom of the $\mathrm{ZnO}$ nanorods, which means the evaporated gold particles did not reach the FTO conductive layer. The uncoated area, which is indicated by the blue dot in Figure $2 \mathrm{a}$ is shown in Figure $2 \mathrm{~d}$ and $2 \mathrm{f}$, presents a smooth and clean nanorod surface in contrast to the gold coated surfaces.
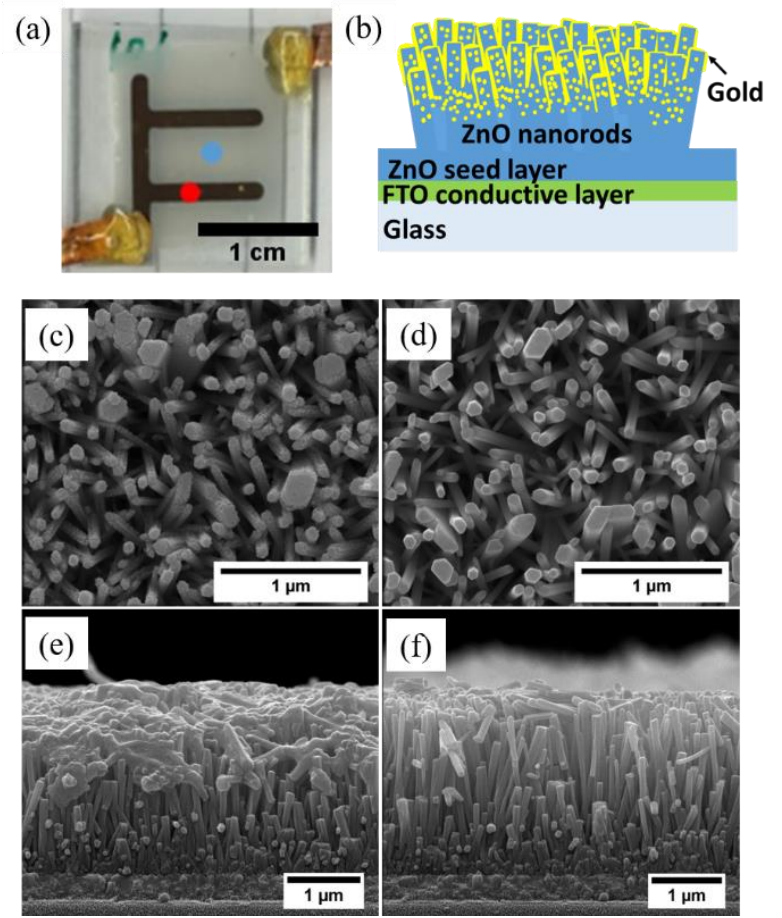

Figure 2 (a) Device photo, the red and blue dots indicate the gold-coated and uncoated areas. (b) A device schematic of its side view. Top-view SEM images of (c) gold-coated area, (d) uncoated area, with corresponding cross-section SEM images in (e) and (f).

Metals have different functions when in contact with semiconductors depending on their size. To study the morphology of gold that was deposited on the $\mathrm{ZnO}$ nanorod surface, TEM images were taken (Figure 3). Figure 3a shows a single nanorod with gold nanoparticles randomly distributed. From the high-magnification TEM image in Figure $3 \mathrm{~b}$, the lattice spacing was determined to be $2.35 \pm 0.01 \AA$, which agrees with the internal lattice spacing of the (111) plane of face-centred-cubic (fcc) gold ( $d=2.355 \AA$, ICCD 
Card No. 04-0784). Figure 3c shows the histogram of the gold nanoparticle size distribution; an average diameter of $5.7 \mathrm{~nm}$ was determined.

(a)

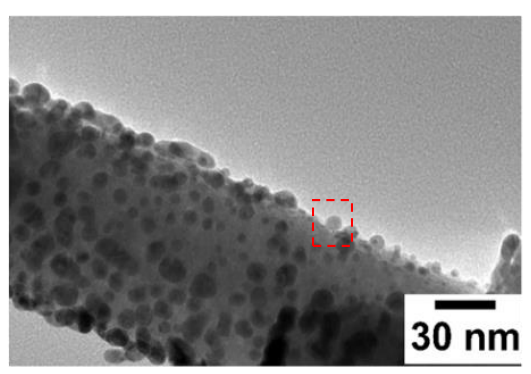

(b)

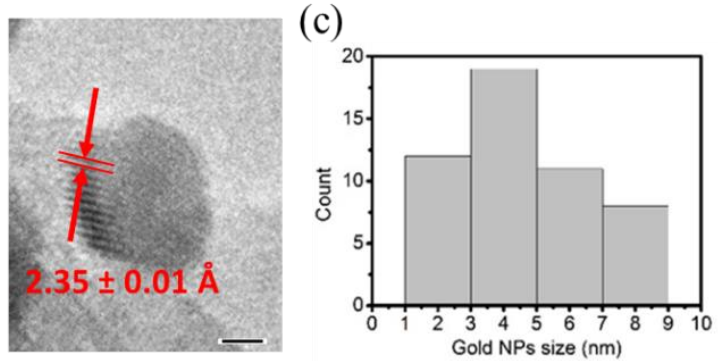

Figure 3 (a) TEM image of $\mathrm{ZnO}$ nanorod with gold nanoparticles. (b) Higher magnification indicated in (a) with clear lattice spacing information, scale bar $2 \mathrm{~nm}$. (c) Gold nanoparticle size distribution.

According to the SEM and TEM images, there were two forms of gold, which were particles on the middle of the nanorods and a film on the top of the nanorods. This formation of both gold nanoparticles and a film is likely because of the vacuum thermal evaporation process. The gold could penetrate to the lower part of the nanorods because the gaps between the nanorods were open at the beginning of the evaporation process; later a film formed on the top and no more gold could penetrate into the spaces between the nanorods (see the device schematic in Figure 2b).

The band gap $\left(\mathrm{E}_{\mathrm{g}}\right)$ of $\mathrm{ZnO}$ nanorods was calculated to be $3.24 \mathrm{eV}$ from the Tauc plot (Figure 4b) which was acquired from the UV-Vis spectrum (Figure 4a). The valance band maximum (VBM) of $\mathrm{ZnO}$ nanorods was obtained from ultraviolet photo-electron spectroscopy (UPS) according to the following equation: ${ }^{48,49}$

$$
\mathrm{VBM}=\mathrm{h} v-\left(E_{\text {cutoff }}-E_{\text {onset }}\right)
$$

where $\mathrm{h} v=21.22 \mathrm{eV}$ is the incident photon energy, $\mathrm{E}_{\text {cutoff }}$ is the electron cut off energy and $\mathrm{E}_{\text {onset }}$ is the onset relative to the Fermi level $\left(\mathrm{E}_{\mathrm{f}}\right)$ of $\mathrm{Au}$ at $0 \mathrm{eV}$. The $\mathrm{E}_{\text {cutoff }}$ of $17.38 \mathrm{eV}$ and the $\mathrm{E}_{\text {onset }}$ of $4.04 \mathrm{eV}$ were determined from Figure $4 \mathrm{c}$ and d, respectively. Therefore, 
the VBM was $7.88 \mathrm{eV}$, and a conduction band minimum (CBM) of $4.64 \mathrm{eV}$ was obtained. The resulting energy band diagram of $\mathrm{ZnO}$ nanorods is shown in Figure 4e. The work function of gold is $5.31 \mathrm{eV} .{ }^{50}$ Theoretically, therefore, a Schottky barrier will form when a large work function noble metal is in contact with $\mathrm{ZnO}$. Figure $\mathrm{S} 1$ shows the $I-V$ curve of the $\mathrm{ZnO} / \mathrm{Au}$ contact; the rectifying behavior demonstrates that a barrier was produced successfully. The rectification ratio at $\pm 1 \mathrm{~V}$ was 1400 .

(a)

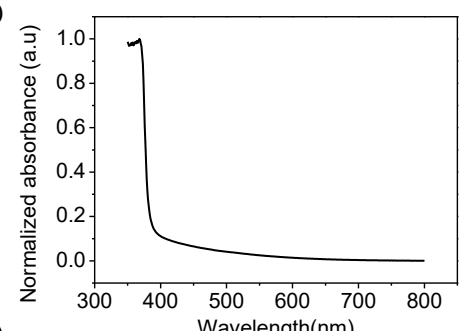

(c)

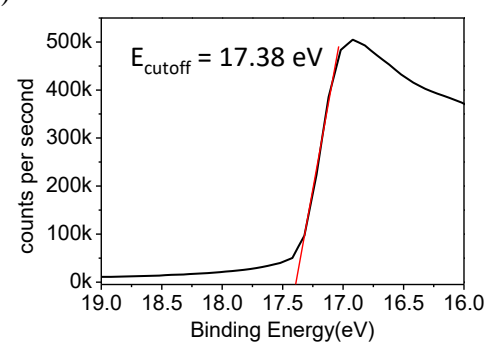

(b)

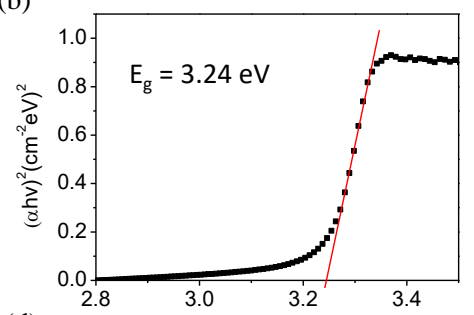

(d)

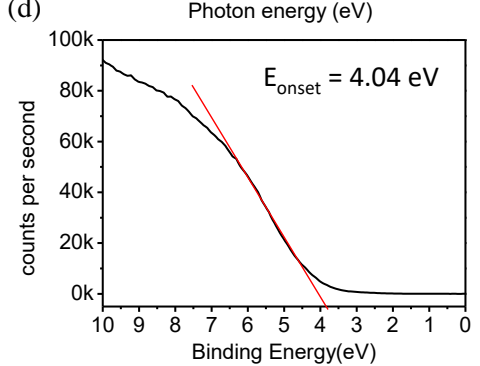

(e)

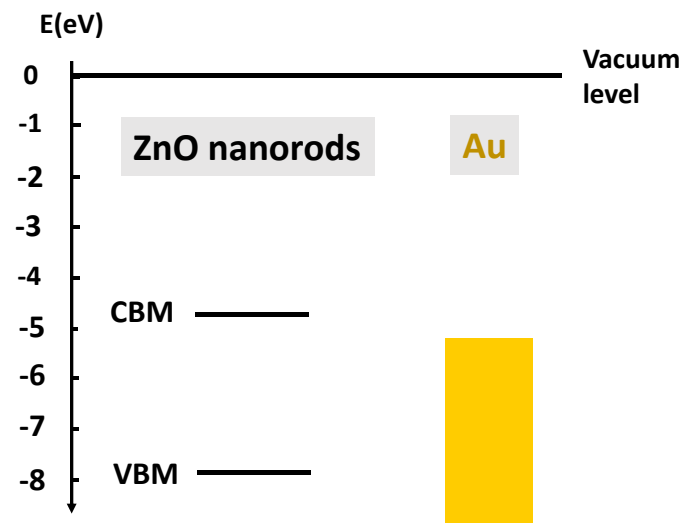

Figure 4 (a) UV-Vis spectrum of $\mathrm{ZnO}$ nanorods. (b) Tauc-plot of $\mathrm{ZnO}$ nanorods, indicates the band gap was $3.24 \mathrm{eV}$. UPS spectrum of $\mathrm{ZnO}$ (c) cut off region; (d) onset region. (e) Energy-band diagram of $\mathrm{ZnO}$ and gold.

\section{Gas sensing properties of ZnO/Au Schottky diodes}

The resistance of a $\mathrm{ZnO} / \mathrm{Au}$ Schottky diode sensor at room temperature was recorded against time at a constant bias of $0.5 \mathrm{~V}$ (Figure $5 \mathrm{a}$ ). Increasing concentrations of $\mathrm{NH}_{3}$ were applied to the sensor in $0 \%, 10 \%$ and $20 \%$ relative humidity. The sensor was exposed to synthetic air before and after gas pulses to establish a baseline resistance. The current of the $\mathrm{ZnO} / \mathrm{Au}$ Schottky diode gas sensor increased rapidly in the presence of $\mathrm{NH}_{3}$. When the chamber was purged with synthetic air, the current returned to the baseline as the oxygen molecules adsorbed on $\mathrm{ZnO}$ again. The sensors showed an increase in the response with increasing $\mathrm{NH}_{3}$ concentration. The as-prepared device showed a large baseline drift of $13 \mu \mathrm{A} / \mathrm{min}$. Exposure to $20 \%$ humidity was found to improve baseline stability to $<2 \mu \mathrm{A} / \mathrm{min}$ over 9 hours and also increase response and recovery rates. At $10 \mathrm{ppm} \mathrm{NH}_{3}$, the response time t90 was approximately 28 min in dry 
air and 3 min at $20 \%$ humidity, while the recovery times were longer with 74 min in dry air and $20 \mathrm{~min}$ at $20 \%$ humidity. The longer recovery times are probably due to slow desorption rates of reaction products from the surface. Operating the sensor at slightly elevated temperature is likely to increase desorption rates and accelerate the recovery. Increasing humidity reduced the overall sensor responsivity (Figure 5c), although the ability of the sensor to discriminate concentrations within the concentration range investigated remains approximately the same. The overall current increased with increasing humidity. This could be due to the adsorption of water on the $\mathrm{ZnO}$ surface and its subsequent dissociation into hydroxide and protons, which could lead to enhanced conductivity due to a proton hopping mechanism. ${ }^{51}$ The presence of water would also allow ammonia to adsorb onto the surface as ammonium hydroxide, which could enhance its reactivity and explain the faster response at higher humidity.

The responsivity of the sensor varies between $8 \%$ and $18 \%$ within the concentration range of ammonia investigated. Further improvement in the sensor response might be achieved by optimising the gold loading of the $\mathrm{ZnO}$ nanorods. ${ }^{32}$ 
(a)

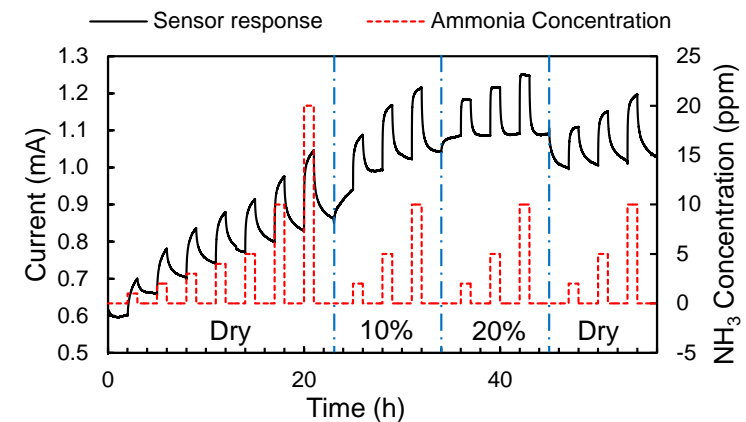

(b)

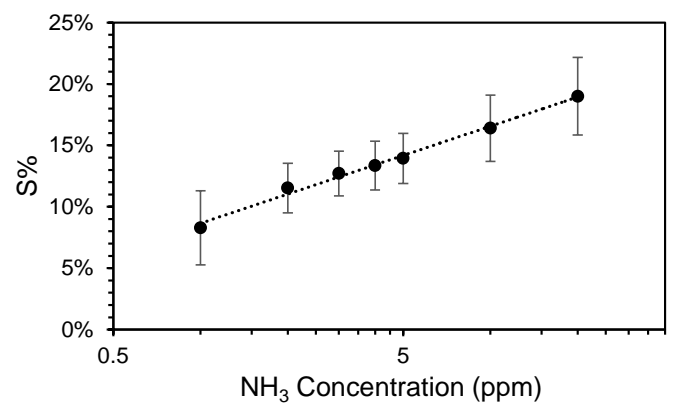

(c)

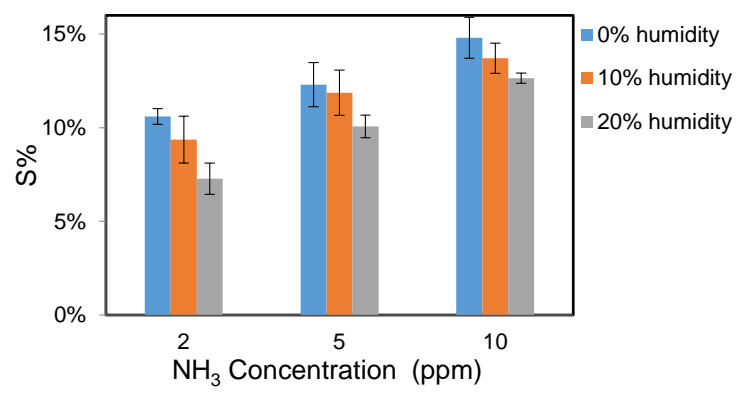

Figure 5 (a) Current change of a $\mathrm{ZnO} / \mathrm{Au}$ Schottky diode versus time at different concentrations of $\mathrm{NH}_{3}$ gas in dry air, $10 \%$ and $20 \%$ humidity, tested at room temperature with a forward bias of $0.5 \mathrm{~V}$. (b) The responsivity $(\mathrm{S} \%)$ versus $\mathrm{NH}_{3}$ concentration at room temperature in dry air; the trendline was obtained by fitting with $y=$ $a+b \ln (x)$ with $\mathrm{a}=0.0866$ and $\mathrm{b}=0.0343$. (c) Comparison of $\mathrm{S} \%$ in dry air, $10 \%$ and $20 \%$ humidity.

At temperatures below $100{ }^{\circ} \mathrm{C}$, oxygen molecules are known to be ionized to $\mathrm{O}_{2}{ }^{-}$at the air- $\mathrm{ZnO}$ interface. It is, therefore, proposed that the chemically active oxygen ions and the trace $\mathrm{NH}_{3}$ molecules reacted at the gas-solid interface as follows: ${ }^{32}$

$$
4 \mathrm{NH}_{3}+3 \mathrm{O}_{2}^{-} \rightarrow 2 \mathrm{~N}_{2}+6 \mathrm{H}_{2} \mathrm{O}+3 \mathrm{e}^{-}
$$

The redox reaction released the trapped electrons back to $\mathrm{ZnO}$ resulting in an increased electron concentration in the conduction band, therefore, the current increased. As the $\mathrm{NH}_{3}$ concentration increased, the current in the Schottky diode increased further as more electrons were released by the reaction. The largest power consumption was $625 \mu \mathrm{W}$ in 
$20 \mathrm{ppm} \mathrm{NH}_{3}$ at $20 \%$ humidity. The responsivity $\mathrm{S} \%$ was used to study the relationship between the current change and $\mathrm{NH}_{3}$ concentration, which can be expressed as

$$
S \%=\frac{I_{\text {gas }}-I_{\text {air }}}{I_{\text {air }}} \times 100 \%
$$

where $I_{g a s}$ is the value of the current measured in gas and $I_{a i r}$ is the base line of current measured in synthetic air. As shown in Figure 5b, the responsivity to $\mathrm{NH}_{3}$ increased with an increasing concentration at room temperature, which gave evidence that a Schottky diode structure can work at decreased operating temperatures. The responsivity shows a non-linear relationship with the $\mathrm{NH}_{3}$ concentration, which can be fitted by a power law. Sensor responses to $\mathrm{NH}_{3}$ at room temperature have also been reported by Shingange et al. with a resistive metal oxide gas sensor based on gold nanoparticle modified $\mathrm{ZnO}$ nanorods. ${ }^{32}$ While the authors did not report absolute resistances, another report of gold decorated $\mathrm{ZnO}$ nanorods deposited onto interdigitated electrodes indicates resistances of the order of several $\mathrm{M} \Omega,{ }^{26}$ while the Schottky diode presented in this work has the advantage of low resistance $<1 \mathrm{k} \Omega$, which makes this device promising for commercial applications.

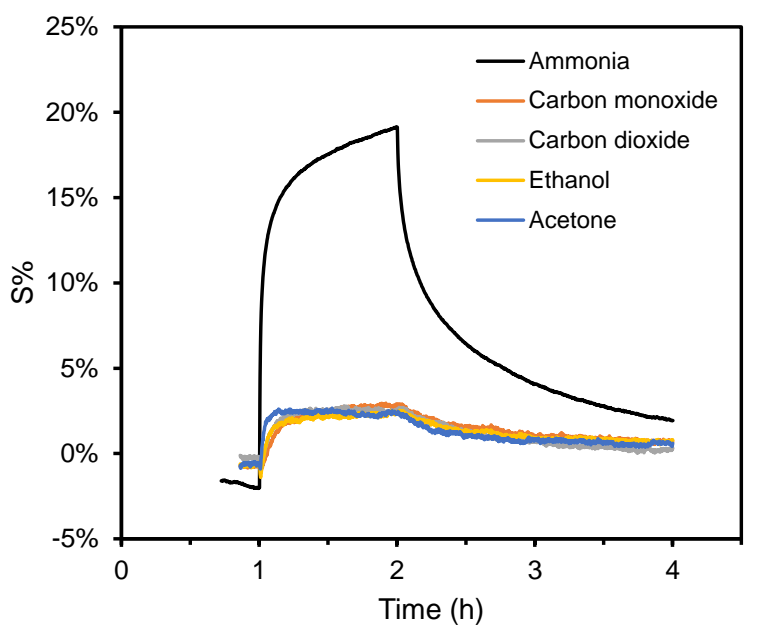

Figure 6 Responses of $\mathrm{ZnO} / \mathrm{Au}$ Schottky diode sensor to different gases of $40 \mathrm{ppm}$ concentration at room temperature, the $\mathrm{NH}_{3}$ concentration was set to be $20 \mathrm{ppm}$.

A traditional conductometric MOS gas sensor device has a chemically active semiconductor layer on an IDE substrate with a heater on the back of the sensor chip. It measures the resistance change across the grain boundaries at high operating 
temperatures. ${ }^{10}$ To study the function of the Schottky gas sensor, conventional MOS gas sensor devices made of $\mathrm{ZnO}$ nanorods on IDEs were investigated for comparison. Figure S2 shows that the current under the same applied bias of $0.5 \mathrm{~V}$ was about twenty times smaller for $\mathrm{ZnO}$ nanorods on an IDE than in the $\mathrm{ZnO} / \mathrm{Au}$ Schottky diode. The current of $\mathrm{ZnO}$ nanorods on the IDE substrate in the air was not stable and did not change significantly after exposure to $50 \mathrm{ppm} \mathrm{NH}_{3}$. This indicates that the Schottky barrier and the current flow along the entire length of the $\mathrm{ZnO}$ nanorods is essential for obtaining a good room temperature response to ammonia.

(a)

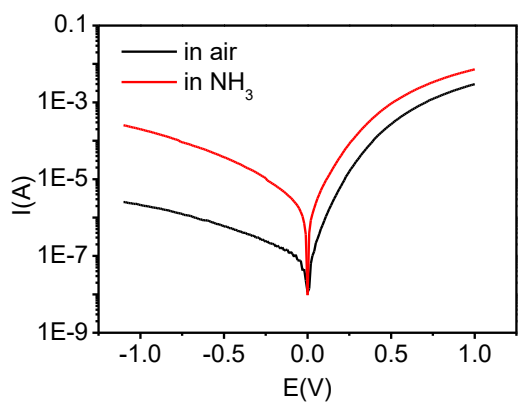

(b)

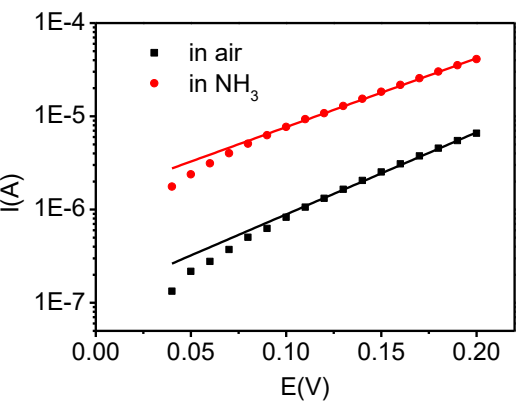

(c)

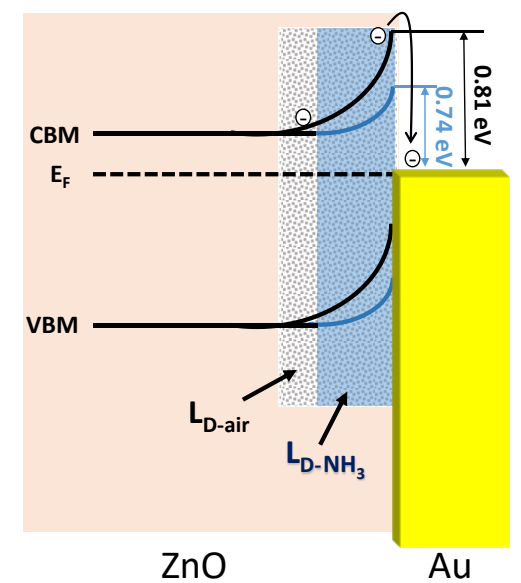

Figure 7 Semilogarithmic presentation of the $I-V$ curves of a $\mathrm{ZnO} / \mathrm{Au}$ Schottky diode at room temperature in air and 40 ppm $\mathrm{NH}_{3}$ (a) from -1 to $+1 \mathrm{~V}$, (b) for forward voltages, (c) energy band configuration of a ZnO/Au Schottky diode gas sensor with a forward voltage 
Selectivity is one of the most important properties in sensing devices. Figure 6 shows the responsivity of a $\mathrm{ZnO} / \mathrm{Au}$ Schottky diode sensor to some of the most common gas analytes with a concentration of $40 \mathrm{ppm}$. The responsivity to $\mathrm{NH}_{3}$ was more than six times greater than that to other gases. This is in agreement with a previous study where the response of gold modified $\mathrm{ZnO}$ nanorods to a wider range of reducing gases, including methane and hydrogen was shown to be small compared to the response to $\mathrm{NH}_{3} .{ }^{32}$ This is likely because $\mathrm{NH}_{3}$ was more active at room temperature than other gases to react with ionized oxygen species $\left(\mathrm{O}_{2}^{-}\right)$at the interface.

\section{Mechanism of a $\mathrm{ZnO} / \mathrm{Au}$ Schottky diode gas sensor}

To understand the mechanism of the $\mathrm{ZnO} / \mathrm{Au}$ Schottky diode as $\mathrm{NH}_{3}$ gas sensor at room temperature, the electrical properties were studied by measuring the $I-V$ curves in air and in $\mathrm{NH}_{3}$, respectively. The Schottky diode displayed a rectification ratio of 1400 in air and 36 in 40 ppm $\mathrm{NH}_{3}$ at $\pm 1 \mathrm{~V}$ at room temperature as shown in Figure $7 \mathrm{a}$. The $I-V$ curves seem to indicate a five times higher sensitivity of the sensor to ammonia under reverse bias conditions; however, dynamic measurements at negative voltages did not produce any significant gas responses within the time frame investigated. With the assumption that the current is due to the thermionic emission, the relation between the applied forward bias and current can be expressed according to the thermionic emission theory as ${ }^{52}$

$$
\mathrm{I}=I_{0} \exp \left(\frac{q V}{n k T}\right)\left[1-\exp \left(\frac{-q V}{k T}\right)\right]
$$

where $\mathrm{n}$ is the ideality factor, $\mathrm{T}$ is the temperature in Kelvin, $\mathrm{q}$ is the electron charge, $\mathrm{k}$ is the Boltzmann constant and $I_{0}$ is the reverse saturation current, at room temperature $(293 \mathrm{~K}), \mathrm{kT} / \mathrm{q}=$ $0.025 \mathrm{~V}$. For V > kT/q, Equation 4 can be written as

$$
\mathrm{I}=I_{0} \exp \left(\frac{q V}{n k T}\right)
$$

The reverse saturation current can be extracted by extrapolating the straight line of $\ln I v s . V$ to intercept the axis at zero voltage:

$$
\ln I=\ln I_{0}+\frac{q}{n k T} V
$$

The forward current increases rapidly with increasing bias; $I_{0}$ and $\mathrm{n}$ can be determined by fitting the linear region of the $\ln I v s . V$ plot as shown in Figure $7 \mathrm{~b}$. Assuming that thermionic emission is the most predominant mechanism, $I_{0}$ can be expressed as ${ }^{43}$ 


$$
I_{0}=A A^{*} T^{2} \exp \left(\frac{-q \Phi_{b}}{k T}\right)
$$

Where $\mathrm{A}$ is the effective diode area, $\mathrm{A}^{*}$ is the effective Richardson constant which is equal to $32 \mathrm{Acm}^{-2} \mathrm{~K}^{-2}$ for $\mathrm{ZnO}{ }^{53}$ and $\Phi_{\mathrm{b}}$ is the zero-bias barrier height. The value $\Phi_{\mathrm{b}}$ in air and in $\mathrm{NH}_{3}$ were determined to be $0.81 \mathrm{eV}$ and $0.74 \mathrm{eV}$. The barrier height at zero-bias of the $\mathrm{ZnO} / \mathrm{Au}$ Schottky diode was smaller in $\mathrm{NH}_{3}$ than in air. With a forward bias of $0.5 \mathrm{~V}$, the released electrons from the redox reaction were easily transferred across the smaller barrier height resulting in a decreased resistance when $\mathrm{NH}_{3}$ gas molecules were introduced (see Figure 7c). Furthermore, with more electrons in the conduction band, they will occupy higher energy states based on the Fermi-Dirac distribution, so a higher proportion will have energies above the barrier height. The width of the depletion layer in air $\left(\mathrm{L}_{\mathrm{D} \text {-air }}\right)$ was greater than that in $\mathrm{NH}_{3}\left(\mathrm{~L}_{\mathrm{D}-\mathrm{NH}}\right)$ due to the increase in the number of charge carriers in $\mathrm{NH}_{3}$. The reverse saturated currents were also in agreement with the calculated change in barrier heights, as a higher current was recorded in $\mathrm{NH}_{3}$. Therefore, by determining the barrier heights and reverse saturated currents of the diode sensors, the detection of $\mathrm{NH}_{3}$ at room temperature is based on the difference of barrier height in different atmospheres.

Another possible mechanism is either the chemical or electronic sensitization by gold nanoparticles on the surface of $\mathrm{ZnO}$. Ramgir et al. have reported a room temperature gas sensor of gold nanoparticles dispersed on $\mathrm{ZnO}$ nanorods that can detect $\mathrm{H}_{2} \mathrm{~S}$ due to catalytic and electronic sensitization effects. ${ }^{54}$ The spill-over effect of $\mathrm{Au}$ nanoparticles on $\mathrm{ZnO}$ nanorods proposed by Shingange et al. also explained Au could enhance responsivity and selectivity to ammonia gas. ${ }^{32}$ At room temperature, Au nanoparticles would facilitate oxygen molecule ionization, in which those oxygen ions could migrate to $\mathrm{ZnO}$ surface. The gold nanoparticles as shown in Figure 2a could act as a chemical promotor to decrease the reactive energy of $\mathrm{NH}_{3}$ molecules and oxygen at the $\mathrm{ZnO}$ surface, which would give good responsivity and selectivity to $\mathrm{NH}_{3}$ at room temperature.

\section{Conclusions}

A $\mathrm{ZnO} / \mathrm{Au}$ Schottky diode gas sensor with vertical architecture was produced using a simple, cost-effective method by depositing gold onto $\mathrm{ZnO}$ nanorods by thermal evaporation. TEM and SEM images confirmed that the gold not only formed as a film on the top but also nanoparticles 
in the center of the nanorods. A rectification ratio of 1400 at $\pm 1 \mathrm{~V}$ was determined by I-V characteristics. Gas sensing tests at room temperature showed that the $\mathrm{ZnO} / \mathrm{Au}$ Schottky diode gas sensor had significant responsivity below $20 \mathrm{ppm} \mathrm{NH}_{3}$ and a promising selectivity compared to some common gases such as acetone, carbon monoxide, and ethanol. Continuous measurements over $24 \mathrm{~h}$ of $\mathrm{ZnO} / \mathrm{Au}$ Schottky diodes showed that the electrical properties were stable. The mechanism of $\mathrm{NH}_{3}$ detection at low temperature was determined by the difference in barrier height of the $\mathrm{ZnO} / \mathrm{Au}$ Schottky diode in different atmospheres. The gold nanoparticles on the $\mathrm{ZnO}$ nanorod surface also may act as a catalyst to enhance the responsivity and selectivity. The successful demonstration of the Schottky diode made with $\mathrm{ZnO}$ nanorods and gold gives an alternative and simple way to decrease the operating temperature, making it possible to be integrated with portable wireless devices

\section{Acknowledgements}

We dedicate this paper to the late Dr. Russell Binions, without whose ideas and expertise in gas sensor characterization, this work would not have been possible. The authors are grateful to the China Scholarship Council for providing PhD studentships to Y. Tu and H. Luo, to the EU for providing a Marie Skłodowska-Curie Individual Fellowship to A. Das (H2020-MSCA-IF-2016745820), to Xi'an Jiaotong University for providing a Young Talent Support Plan to D. Zhang (YX6J003) and to BBSRC (BB/P026788/1) and EPSRC (EP/R035571/1) for funding and Thermo Fisher Scientific, UK, for carrying out UPS measurements.

\section{Supporting information}

This paper is accompanied by supporting information containing:

- Current-voltage curve of a $\mathrm{ZnO} / \mathrm{Au}$ Schottky diode

- Ammonia response of $\mathrm{ZnO}$ nanorods deposited on an interdigitated transducer.

\section{References:}

(1) Wang, S.; Nan, J.; Shi, C.; Fu, Q.; Gao, S.; Wang, D.; Cui, H.; Saiz-Lopez, A.; Zhou, B. Atmospheric Ammonia and Its Impacts on Regional Air Quality over the Megacity of Shanghai, China. Sci. Rep. 2015, 5 (1), 15842. https://doi.org/10.1038/srep15842.

(2) Behera, S. N.; Sharma, M.; Aneja, V. P.; Balasubramanian, R. Ammonia in the Atmosphere: A Review on Emission Sources, Atmospheric Chemistry and Deposition on Terrestrial Bodies. Environ. Sci. Pollut. Res. 2013, 20 (11), 8092-8131. 
https://doi.org/10.1007/s11356-013-2051-9.

(3) Klerke, A.; Christensen, C. H.; Nørskov, J. K.; Vegge, T. Ammonia for Hydrogen Storage: Challenges and Opportunities. J. Mater. Chem. 2008, 18 (20), 2304-2310. https://doi.org/10.1039/b720020j.

(4) Lan, R.; Irvine, J. T. S.; Tao, S. Ammonia and Related Chemicals as Potential Indirect Hydrogen Storage Materials. Int. J. Hydrogen Energy 2012, 37 (2), 1482-1494. https://doi.org/10.1016/j.ijhydene.2011.10.004.

(5) Zamfirescu, C.; Dincer, I. Ammonia as a Green Fuel and Hydrogen Source for Vehicular Applications. Fuel Process. Technol. 2009, $90 \quad$ (5), 729-737. https://doi.org/10.1016/j.fuproc.2009.02.004.

(6) SAIF. Safety topic - $\quad$ Ammonia https://www.saif.com/Documents/SafetyandHealth/Chemicals/SS416_ammonia.pdf.

(7) Kolmakov, A.; Zhang, Y.; Cheng, G.; Moskovits, M. Detection of $\mathrm{CO}$ and $\mathrm{O}_{2}$ Using Tin Oxide Nanowire Sensors. Adv. Mater. 2003, 15 (12), 997-1000. https://doi.org/10.1002/adma.200304889.

(8) Niu, S.; Hu, Y.; Wen, X.; Zhou, Y.; Zhang, F.; Lin, L.; Wang, S.; Wang, Z. L. Enhanced Performance of Flexible $\mathrm{ZnO}$ Nanowire Based Room-Temperature Oxygen Sensors by Piezotronic Effect. Adv. Mater. 2013, 25 (27), 3701-3706. https://doi.org/10.1002/adma.201301262.

(9) Barsan, N.; Koziej, D.; Weimar, U. Metal Oxide-Based Gas Sensor Research: How To? Sensors Actuators, B Chem. 2007, $121 \quad$ (1), 18-35. https://doi.org/10.1016/j.snb.2006.09.047.

(10) Fine, G. F.; Cavanagh, L. M.; Afonja, A.; Binions, R. Metal Oxide Semi-Conductor Gas Sensors in Environmental Monitoring. Sensors 2010, 10 (6), 5469-5502. https://doi.org/10.3390/s100605469.

(11) Wang, C.; Cui, X.; Liu, J.; Zhou, X.; Cheng, X.; Sun, P.; Hu, X.; Li, X.; Zheng, J.; Lu, G. Design of Superior Ethanol Gas Sensor Based on Al-Doped NiO Nanorod-Flowers. ACS Sensors 2016, 1 (2), 131-136. https://doi.org/10.1021/acssensors.5b00123.

(12) Zou, Y.; Chen, S.; Sun, J.; Liu, J.; Che, Y.; Liu, X.; Zhang, J.; Yang, D. Highly Efficient Gas Sensor Using a Hollow $\mathrm{SnO}_{2}$ Microfiber for Triethylamine Detection. ACS Sensors 2017, 2 (7), 897-902. https://doi.org/10.1021/acssensors.7b00276.

(13) Vallejos, S.; Umek, P.; Stoycheva, T.; Annanouch, F.; Llobet, E.; Correig, X.; De Marco, P.; Bittencourt, C.; Blackman, C. Single-Step Deposition of Au- and Pt-NanoparticleFunctionalized Tungsten Oxide Nanoneedles Synthesized via Aerosol-Assisted CVD, and Used for Fabrication of Selective Gas Microsensor Arrays. Adv. Funct. Mater. 2013, 23 (10), 1313-1322. https://doi.org/10.1002/adfm.201201871.

(14) Yoon, D. H.; Choi, G. M. Microstructure and CO Gas Sensing Properties of Porous ZnO Produced by Starch Addition. Sensors Actuators, B Chem. 1997, 45 (3), 251-257. https://doi.org/10.1016/S0925-4005(97)00316-X. 
(15) Chinh, N. D.; Quang, N. D.; Lee, H.; Hien, T. T.; Hieu, N. M.; Kim, D.; Kim, C.; Kim, D. NO Gas Sensing Kinetics at Room Temperature under UV Light Irradiation of $\mathrm{In}_{2} \mathrm{O}_{3}$ Nanostructures. Sci. Rep. 2016, 6 (1), 35066. https://doi.org/10.1038/srep35066.

(16) Sturaro, M.; Della Gaspera, E.; Michieli, N.; Cantalini, C.; Emamjomeh, S. M.; Guglielmi, M.; Martucci, A. Degenerately Doped Metal Oxide Nanocrystals as Plasmonic and Chemoresistive Gas Sensors. ACS Appl. Mater. Interfaces 2016, 8 (44), 30440-30448. https://doi.org/10.1021/acsami.6b09467.

(17) Hoffmann, M. W. G.; Mayrhofer Dr, L.; Casals Dr, O.; Caccamo, L.; Hernez-Ramirez, F.; Lilienkamp, G.; Daum, W.; Moseler, M.; Waag, A.; Shen, H.; Prades, J. D. A Highly Selective and Self-Powered Gas Sensor via Organic Surface Functionalization of p-Si/n$\mathrm{ZnO}$ Diodes. Adv. Mater. 2014, $26 \quad$ (47), 8017-8022. https://doi.org/10.1002/adma.201403073.

(18) Park, S.; An, S.; Mun, Y.; Lee, C. UV-Enhanced $\mathrm{NO}_{2}$ Gas Sensing Properties of $\mathrm{SnO}_{2}-$ Core/ZnO-Shell Nanowires at Room Temperature. ACS Appl. Mater. Interfaces 2013, 5 (10), 4285-4292. https://doi.org/10.1021/am400500a.

(19) Fu, Y.; Nie, Y.; Zhao, Y.; Wang, P.; Xing, L.; Zhang, Y.; Xue, X. Detecting Liquefied Petroleum Gas (LPG) at Room Temperature Using $\mathrm{ZnSnO}_{3} / \mathrm{ZnO}$ Nanowire PiezoNanogenerator as Self-Powered Gas Sensor. ACS Appl. Mater. Interfaces 2015, 7 (19), 10482-10490. https://doi.org/10.1021/acsami.5b01822.

(20) Modaresinezhad, E.; Darbari, S. Realization of a Room-Temperature/Self-Powered Humidity Sensor, Based on ZnO Nanosheets. Sensors Actuators, B Chem. 2016, 237, 358-366. https://doi.org/10.1016/j.snb.2016.06.097.

(21) Xue, X.; Fu, Y.; Wang, Q.; Xing, L.; Zhang, Y. Outputting Olfactory Bionic Electric Impulse by PANI/PTFE/PANI Sandwich Nanostructures and Their Application as Flexible, Smelling Electronic Skin. Adv. Funct. Mater. 2016, 26 (18), 3128-3138. https://doi.org/10.1002/adfm.201505331.

(22) Chen, C.; Zhang, Q.; Xie, G.; Yao, M.; Pan, H.; Du, H.; Tai, H.; Du, X.; Su, Y. Enhancing Visible Light-Activated $\mathrm{NO}_{2}$ Sensing Properties of Au NPs Decorated ZnO Nanorods by Localized Surface Plasmon Resonance and Oxygen Vacancies. Mater. Res. Express 2020, 7 (1), 015924. https://doi.org/10.1088/2053-1591/ab6b64.

(23) Wang, J.; Fan, S.; Xia, Y.; Yang, C.; Komarneni, S. Room-Temperature Gas Sensors Based on ZnO Nanorod/Au Hybrids: Visible-Light-Modulated Dual Selectivity to $\mathrm{NO}_{2}$ $\begin{array}{lllllll}\text { and } \mathrm{NH}_{3} . & \text { J. Hazard. } & \text { Mater. 2020, } & 381 & \text { (381), } & 120919 .\end{array}$ https://doi.org/10.1016/j.jhazmat.2019.120919.

(24) Wang, Z.; Tian, Z.; Han, D.; Gu, F. Au-Modified Three-Dimensionally Ordered Macroporous ZnO:In for High-Performance Ethanol Sensors. J. Mater. Chem. C 2020, 8 (8), 2812-2819. https://doi.org/10.1039/c9tc06750g.

(25) Suematsu, K.; Watanabe, K.; Tou, A.; Sun, Y.; Shimanoe, K. Ultraselective Toluene-Gas Sensor: Nanosized Gold Loaded on Zinc Oxide Nanoparticles. Anal. Chem. 2018, 90 (3), 1959-1966. https://doi.org/10.1021/acs.analchem.7b04048. 
(26) Dinesh, V. P.; Biji, P.; Prasad, A. K.; Tyagi, A. K. Enhanced Ammonia Sensing Properties Using Au Decorated ZnO Nanorods. In Proceedings of IEEE Sensors; IEEE, 2013; 1-4. https://doi.org/10.1109/ICSENS.2013.6688189.

(27) Cho, H. J.; Chen, V. T.; Qiao, S.; Koo, W. T.; Penner, R. M.; Kim, I. D. Pt-Functionalized PdO Nanowires for Room Temperature Hydrogen Gas Sensors. ACS Sensors 2018, 3 (10), 2152-2158. https://doi.org/10.1021/acssensors.8b00714.

(28) Choi, S. W.; Katoch, A.; Sun, G. J.; Kim, S. S. Bimetallic Pd/Pt NanoparticleFunctionalized $\mathrm{SnO}_{2}$ Nanowires for Fast Response and Recovery to $\mathrm{NO}_{2}$. Sensors Actuators, B Chem. 2013, 181, 446-453. https://doi.org/10.1016/j.snb.2013.02.007.

(29) Wang, Z.; Li, Z.; Jiang, T.; Xu, X.; Wang, C. Ultrasensitive Hydrogen Sensor Based on Pd0-Loaded $\mathrm{SnO}_{2}$ Electrospun Nanofibers at Room Temperature. ACS Appl. Mater. Interfaces 2013, 5 (6), 2013-2021. https://doi.org/10.1021/am3028553.

(30) Zhang, J.; Liu, X.; Neri, G.; Pinna, N. Nanostructured Materials for Room-Temperature Gas Sensors. Adv. Mater. 2016, 28 (5), 795-831. https://doi.org/10.1002/adma.201503825.

(31) Wang, Y.; Liu, B.; Cai, D.; Li, H.; Liu, Y.; Wang, D.; Wang, L.; Li, Q.; Wang, T. RoomTemperature Hydrogen Sensor Based on Grain-Boundary Controlled Pt Decorated $\mathrm{In}_{2} \mathrm{O}_{3}$ Nanocubes. Sensors Actuators, B Chem. 2014, 201, 351-359. https://doi.org/10.1016/j.snb.2014.05.013.

(32) Shingange, K.; Tshabalala, Z. P.; Ntwaeaborwa, O. M.; Motaung, D. E.; Mhlongo, G. H. Highly Selective $\mathrm{NH}_{3}$ Gas Sensor Based on Au Loaded ZnO Nanostructures Prepared Using Microwave-Assisted Method. J. Colloid Interface Sci. 2016, 479, 127-138. https://doi.org/10.1016/j.jcis.2016.06.046.

(33) Wan, Q.; Li, Q. H.; Chen, Y. J.; Wang, T. H.; He, X. L.; Li, J. P.; Lin, C. L. Fabrication and Ethanol Sensing Characteristics of ZnO Nanowire Gas Sensors. Appl. Phys. Lett. 2004, 84 (18), 3654-3656. https://doi.org/10.1063/1.1738932.

(34) Wen, Z.; Zhu, L.; Zhang, Z.; Ye, Z. Fabrication of Gas Sensor Based on Mesoporous Rhombus-Shaped ZnO Rod Arrays. Sensors Actuators, B Chem. 2015, 208, 112-121. https://doi.org/10.1016/j.snb.2014.11.024.

(35) Jing, Z.; Zhan, J. Fabrication and Gas-Sensing Properties of Porous ZnO Nanoplates. Adv. Mater. 2008, 20 (23), 4547-4551. https://doi.org/10.1002/adma.200800243.

(36) Galstyan, V.; Comini, E.; Baratto, C.; Faglia, G.; Sberveglieri, G. Nanostructured ZnO Chemical Gas Sensors. Ceram. Int. 2015, 41 (10PartB), 14239-14244. https://doi.org/10.1016/j.ceramint.2015.07.052.

(37) Wang, Z.; Xue, J.; Han, D.; Gu, F. Controllable Defect Redistribution of ZnO Nanopyramids with Exposed \{1011\} Facets for Enhanced Gas Sensing Performance. ACS Appl. Mater. Interfaces 2015, 7 (1), 308-317. https://doi.org/10.1021/am506206c.

(38) Tu, Y.; Ahmad, N.; Briscoe, J.; Zhang, D. W.; Krause, S. Light-Addressable Potentiometric Sensors Using ZnO Nanorods as the Sensor Substrate for Bioanalytical $\begin{array}{lllll}\text { Applications. Anal. Chem. 2018, } 90 \quad \text { (14), 8708-8715. } & \text {. }\end{array}$ https://doi.org/10.1021/acs.analchem.8b02244. 
(39) Ahn, M. W.; Park, K. S.; Heo, J. H.; Park, J. G.; Kim, D. W.; Choi, K. J.; Lee, J. H.; Hong, S. H. Gas Sensing Properties of Defect-Controlled ZnO-Nanowire Gas Sensor. Appl. Phys. Lett. 2008, 93 (26), 263103. https://doi.org/10.1063/1.3046726.

(40) Comini, E.; Sberveglieri, G. Metal Oxide Nanowires as Chemical Sensors. Mater. Today 2010, 13 (7-8), 36-44. https://doi.org/10.1016/S1369-7021(10)70126-7.

(41) Barreca, D.; Bekermann, D.; Comini, E.; Devi, A.; Fischer, R. A.; Gasparotto, A.; MacCato, C.; Sada, C.; Sberveglieri, G.; Tondello, E. Urchin-like ZnO Nanorod Arrays for Gas Sensing Applications. CrystEngComm 2010, 12 (11), 3419-3421. https://doi.org/10.1039/c0ce00139b.

(42) Minh Triet, N.; Thai Duy, L.; Hwang, B. U.; Hanif, A.; Siddiqui, S.; Park, K. H.; Cho, C. Y.; Lee, N. E. High-Performance Schottky Diode Gas Sensor Based on the Heterojunction of Three-Dimensional Nanohybrids of Reduced Graphene Oxide-Vertical ZnO Nanorods on an AlGaN/GaN Layer. ACS Appl. Mater. Interfaces 2017, 9 (36), 30722-30732. https://doi.org/10.1021/acsami.7b06461.

(43) Kadir, R. A.; Zhang, W.; Wang, Y.; Ou, J. Z.; Wlodarski, W.; O’Mullane, A. P.; Bryant, G.; Taylor, M.; Kalantar-Zadeh, K. Anodized Nanoporous $\mathrm{WO}_{3}$ Schottky Contact Structures for Hydrogen and Ethanol Sensing. J. Mater. Chem. A 2015, 3 (15), 7994-8001. https://doi.org/10.1039/c4ta06286h.

(44) Luther, B. P.; Wolter, S. D.; Mohney, S. E. High Temperature Pt Schottky Diode Gas Sensors on N-Type GaN. Sensors Actuators, B Chem. 1999, 56 (1), 164-168. https://doi.org/10.1016/S0925-4005(99)00174-4.

(45) Heo, Y. W.; Tien, L. C.; Norton, D. P.; Pearton, S. J.; Kang, B. S.; Ren, F.; LaRoche, J. R. Pt/ZnO Nanowire Schottky Diodes. Appl. Phys. Lett. 2004, 85 (15), 3107-3109. https://doi.org/10.1063/1.1802372.

(46) Das, S. N.; Choi, J. H.; Kar, J. P.; Moon, K. J.; Lee, T. Il; Myoung, J. M. Junction Properties of Au/ZnO Single Nanowire Schottky Diode. Appl. Phys. Lett. 2010, 96 (9), 092111. https://doi.org/10.1063/1.3339883.

(47) Tu, Y.; Chen, S.; Li, X.; Gorbaciova, J.; Gillin, W. P.; Krause, S.; Briscoe, J. Control of Oxygen Vacancies in $\mathrm{ZnO}$ Nanorods by Annealing and Their Influence on ZnO/PEDOT:PSS Diode Behaviour. J. Mater. Chem. C 2018, 6 (7), 1815-1821. https://doi.org/10.1039/c7tc04284a.

(48) Feng, W.; Rangan, S.; Cao, Y.; Galoppini, E.; Bartynski, R. A.; Garfunkel, E. Energy Level Alignment of Polythiophene/ZnO Hybrid Solar Cells. J. Mater. Chem. A 2014, 2 (19), 7034-7044. https://doi.org/10.1039/c4ta00937a.

(49) Ambade, S. B.; Ambade, R. B.; Lee, W.; Mane, R. S.; Yoon, S. C.; Lee, S. H. Development of Highly Transparent Seedless $\mathrm{ZnO}$ Nanorods Engineered for Inverted Polymer Solar Cells. Nanoscale 2014, $6 \quad$ (20), 12130-12141. https://doi.org/10.1039/c4nr03080j.

(50) Skriver, H. L.; Rosengaard, N. M. Surface Energy and Work Function of Elemental

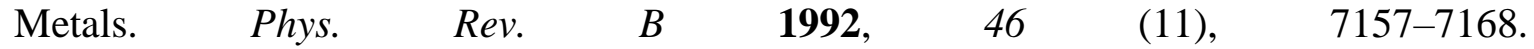


https://doi.org/10.1103/PhysRevB.46.7157.

(51) Chang, P. Y.; Chang, P. Y.; Chang, P. Y.; Lin, C. F.; Lin, C. F.; Lin, C. F.; El Khoury Rouphael, S.; El Khoury Rouphael, S.; Huang, T. H.; Wu, C. M.; Berling, D.; Berling, D.; Yeh, P. H.; Lu, C. J.; Meng, H. F.; Zan, H. W.; Soppera, O.; Soppera, O. Near-Infrared Laser-Annealed IZO Flexible Device as a Sensitive $\mathrm{H}_{2} \mathrm{~S}$ Sensor at Room Temperature. ACS Appl. Mater. Interfaces 2020, $12 \quad$ (22), 24984-24991. https://doi.org/10.1021/acsami.0c03257.

(52) Yakuphanoglu, F.; Basaran, E.; Şenkal, B. F.; Sezer, E. Electrical and Optical Properties of an Organic Semiconductor Based on Polyaniline Prepared by Emulsion Polymerization and Fabrication of Ag/Polyaniline/n-Si Schottky Diode. J. Phys. Chem. B 2006, 110 (34), 16908-16913. https://doi.org/10.1021/jp060445v.

(53) Sarpatwari, K.; Awadelkarim, O. O.; Allen, M. W.; Durbin, S. M.; Mohney, S. E. Extracting the Richardson Constant: IrOx /n-ZnO Schottky Diodes. Appl. Phys. Lett. 2009, 94 (24), 242110. https://doi.org/10.1063/1.3156031.

(54) Ramgir, N. S.; Sharma, P. K.; Datta, N.; Kaur, M.; Debnath, A. K.; Aswal, D. K.; Gupta, S. K. Room Temperature $\mathrm{H}_{2} \mathrm{~S}$ Sensor Based on Au Modified $\mathrm{ZnO}$ Nanowires. Sensors Actuators, B Chem. 2013, 186, 718-726. https://doi.org/10.1016/j.snb.2013.06.070.

TOC graphics:
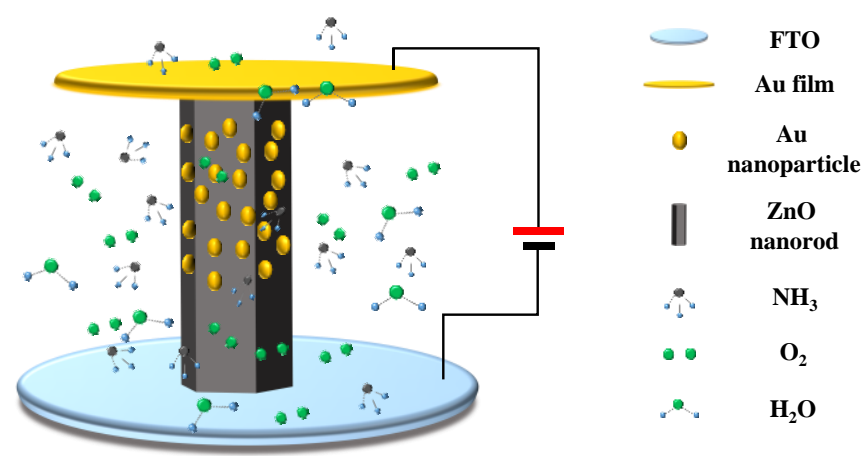